\title{
Factors in the Adjustment and Academic Achievement of College Students with Learning Disabilities in Israel
}

\author{
Hagit Krisher ${ }^{1} \&$ Zipora Shechtman ${ }^{1}$ \\ ${ }^{1}$ Faculty of Education, University of Haifa, Mount Carmel, Haifa, Israel \\ Correspondence: Hagit Krisher, Faculty of Education, University of Haifa, Mount Carmel, Haifa 31905, Israel.
}

Received: November 24, 2015

Accepted: December 24, 2015

Online Published: January 26, 2016

doi:10.5430/irhe.v1n1p125

URL: http://dx.doi.org/10.5430/irhe.v1n1p125

\begin{abstract}
The number of students with learning disabilities (LD) who attend postsecondary education has increased steadily over the past 20 years. This study examines the contribution of internal (academic self-efficacy and attachment style) and external (social support and institutional support) factors to the adjustment and achievement of students with LDs in the academic setting. Participants were 674 students from 24 institutions of higher education in Israel. The experimental group $(n=338)$ consisted of students with self-reported LD, the control group $(n=336)$ were students who reported they did not have an LD. Our hypothesis that students with LD would report lower academic achievements and lower levels of adjustment than would students with no LD was confirmed. A further hypothesis, that internal and external factors would both be associated with adjustment and academic achievements of LD students, was confirmed by a Structural Equation Modeling Analysis. These findings emphasize the importance of social, family and environment in the success of students with LD in higher education.
\end{abstract}

Keywords: higher education, learning disabilities, adjustment, academic achievement

\section{Introduction}

According to the multi-dimensional developmental model, there are mutual relations between an individual and environmental characteristics that affect the academic functioning and adjustment of students with LD. Such students, who constitute a unique sub-group in higher education, require particular attention (Costello \& Stone, 2012), since they face numerous academic, social and emotional challenges in this setting. However, research concerning the functioning and adjustment of this sub-group presents an inconsistent picture. Some studies indicated that these students undergo considerable difficulties in the process of adapting to the academic setting (Heiman, 2006a; Turnbull, Turnbull, \& Wehmeyer, 2010; Weyandt \& DuPaul, 2008), while others showed that many students with LD adjust efficiently and succeed in coping with their difficulties (Shepler \& Woosley, 2012). The mere existence of a disability constitutes a risk factor for adjustment, but it cannot be the sole predictor of adjustment. Rather, a combination of personal, family, and environmental factors is required for such prediction (Hojati \& Abbasi, 2013). Accordingly, the purpose of the current study was to examine internal and external factors that might impact the academic achievement and adjustment of students with LD. The internal factors examined included academic self-efficacy and attachment style, while the external factors were social support and institutional support. The relationships between the internal and external factors were examined using Structural Equation Modeling (see Figure 1). 


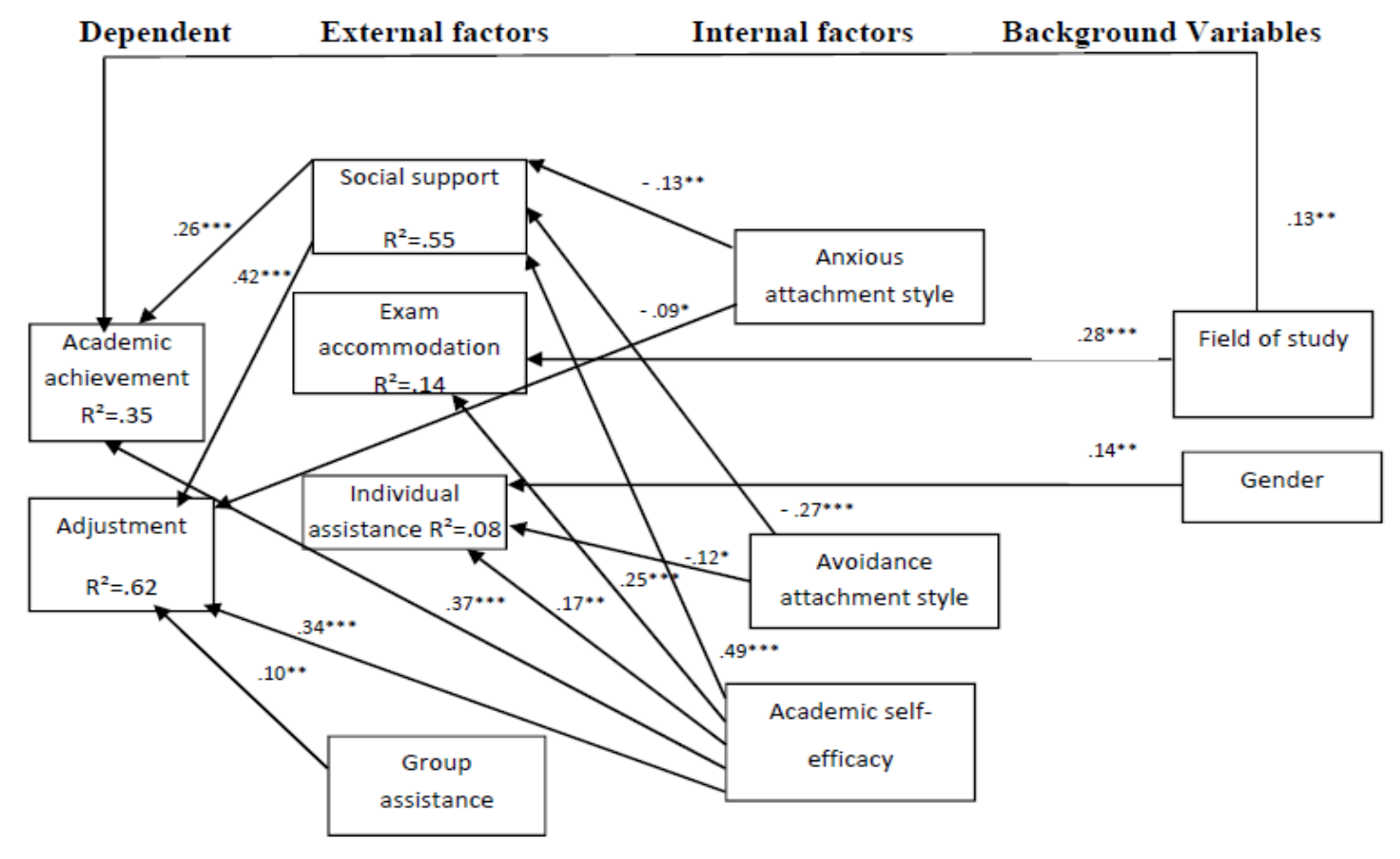

$* \mathrm{p}<.05 ; * * \mathrm{p}<.01 ; * * * \mathrm{p}<.001$.

Figure 1. Structural Equation Model (SEM) to predict the study variables $(\mathrm{N}=338)$

\section{Internal Factors}

\subsection{Academic Self-efficacy}

Academic self-efficacy has been defined as a person's beliefs in his or her abilities to successfully complete learning tasks. Based on cognitive theory (Bandura, 1993), real experiences constitute one of the sources for the development of self-efficacy. Studies indicate that students' past achievements have a significant impact on their sense of academic self-efficacy (Zimmerman, 2008). Thus, learners who have experienced numerous academic failures may have low self-efficacy in this domain (Costello \& Stone, 2012). Another source of self-efficacy is positive messages from "significant others" (Bandura, 1993). Studies show that messages from parents and teachers have a significant impact on students' academic self-efficacy (Schunk \& Pajares, 2009).

A review of the literature on self-efficacy among students with LD produced inconsistent findings. Some studies found this group to have lower levels of academic self-efficacy (Hall \& Webster, 2008; Klassen \& Lynch, 2007), whereas others found no differences in this domain between students with LD and their counterparts (Klassen \& Lynch, 2007). To add to the inconsistency, there are even studies that reported higher levels of self-efficacy and higher academic abilities for LD students (Frazier, Younstrom, Glutting, \& Watkins, 2007; Klassen \& Lynch, 2007). This discrepancy points to the importance of further examination of academic self-efficacy among students with LD and its impact on the academic achievement and adjustment of these students compared to their non-LD peers.

\subsection{Attachment Style}

Attachment means emotional bonds, characterized by seeking proximity to someone (an attachment figure) in stressful situations. Among children, these bonds are based on a child's need for safety, security, and protection (Bowlby, 1980). Infants become attached to a consistent caregiver who is sensitive and responsive, and they use attachment figures (usually a caregiver) as a secure base for exploration. One's experience with attachment figures leads to "internal working models," which are mental representations of significant others and the self. These models, which develop during the child's first years, affect the individual's feelings, thoughts, and expectations in later relationships (Hazan \& Shaver, 1994). Based on observations (Ainsworth, Blehar, Water, \& Wall, 1978), three attachment styles have been identified: secure, anxious, and avoidant. A fourth attachment style was added later (Main \& Solomon, 1986); this style was labeled disorganized. The attachment literature clearly indicates that attachment anxiety and avoidance are positively related to maladjustment, including depression symptoms, increased feelings of loneliness, interpersonal difficulties, and greater hostility toward others, and to emotional distress, such as shame, anger, anxiety, and 
nervousness (Al-Yagon, 2012, 2014; Gresham \& Gullone, 2012). In addition, attachment theory has been considered a highly relevant framework for explaining individual variations in adjustment among at-risk populations, such as persons with LD. However, in contrast to the growing literature on the contribution of attachment style to adjustment, relatively few studies have focused on students with LD (Al-Yagon, 2012, 2014). Accordingly, the current study examined the impact of attachment style on the academic achievement and adjustment of college students with LD and compared these findings to their peers with no LD.

\section{External Factors}

\subsection{Perceived Social Support}

Social support constitutes one of the most protective factors in a student's adjustment to a higher education setting (Bakker, Demerouti, \& Euwema, 2005). A large body of research has found social support to be positively correlated with psychological outcomes, such as greater life satisfaction, as well as lower levels of depression, anxiety, and loneliness (Bakker et al., 2005; Karatepe \& Olugbade, 2009; Yalcin, 2011). Furthermore, social support from parents, peers, and others has been identified as an important protective factor that can enhance positive developmental outcomes among college students in the presence of known risks (Sarason \& Sarason, 2009; Wilks \& Spivey 2010). Although research has shown a positive relationship between social support and psychological functioning in the general population, relatively little is known about the social support of adults with LD. The findings regarding perceived social support of students with LD are, as they were with self-efficacy, inconsistent. Several studies found lower levels of social support among students with LD (Heiman, 2006b), and other studies found social support to be both directly and indirectly related to adjustment and to psychological well-being among students with LD (Murray, Lombardi, Bender \& Gerdes, 2013). Students who received strong support from parents and peers had less difficulty disclosing their disabilities and requesting accommodations in their new educational setting (Murray et al, 2013; Yalcin, 2011). Based on these findings, our goal was to further examine the impact of social support on the academic achievement and adjustment among students with LD in comparison with their non-LD peers.

\subsection{Institutional Support}

The transition from secondary to postsecondary education can be difficult for students with LD (Estrada, Dupoux, \& Wolman, 2006). Often, these students require special support in order to adjust academically and socially to college life (Weyandt \& DuPaul, 2008). The number of support programs available to college students with LD is expanding, but the services offered vary considerably from institution to institution (Lindstrom, 2007). Assistance can be provided by focusing on the development of the individual learner through counseling, coaching, guiding, and therapy. Institutional assistance can include, among other options, accommodation on exams, special tutoring, copies of lecture notes, priority registration, and self-advocacy training (Buchanan, Charles, Ringer, \& Hart, 2010; Lindstrom, 2007; Raue \& Lewis, 2011; Vance \& Weyandt, 2008). Extending appropriate institutional support is critical to the success and retention of college students with LD (Weyandt \& DuPaul, 2008). Without proper institutional support, high percentages of students with LD drop out of high school, do not seek admission to postsecondary education, and are not prepared to succeed in higher education (Estrada et al., 2006). Given the academic challenges that many college students with LD encounter, it seems important to investigate the contribution of institutional support to these students' academic achievement and adjustment.

\section{The Study Hypotheses}

Based on the foregoing literature, the following hypotheses were generated:

4.1 Academic achievement and the adjustment scores of students with LD will be lower than those of students with no LD.

4.2 Scores on anxiety or avoidance attachment styles will be related to students' academic achievements and adjustment.

4.3 Scores on academic self-efficacy will be positively related to academic achievement and level of adjustment.

4.4 Scores on perceived social support will be positively related to academic achievements and adjustment.

4.5 Scores on institutional support will be positively related to academic achievements, adjustment, and academic self- efficacy.

\section{Methodology}

\subsection{Participants}

The study included 674 students from 24 institutions of higher education in Israel. The experimental group consisted of 338 students who reported a diagnosis of LD; the control group consisted of 336 students who reported they had no LD. 
Participants were enrolled in a variety of programs in the social studies, humanities, and sciences. No differences in background characteristics as, age, gender, family status, mother tongue, area of studies and study semester were observed between the two groups of participants, but the experimental group initially showed lower psychometric and GPA scores.

\subsection{Instruments}

5.2.1 The Personal Information Questionnaire is a self-report measure developed for this study. It includes background characteristics: age, gender, family status, institution, program semester, psychometric score, and current GPA (0-100).

5.2.2 Student Adaptation to College Questionnaire (SACQ) (Baker \& Siryk, 1989). The SACQ is a self-report instrument consisting of 67 items and designed to assess four aspects of a student's adjustment to college: academic, social, personal- emotional, and institutional. The SACQ was developed in English and was translated into Hebrew by Khalili (2006) using the standard back-translation method. Participants responded to each of the questionnaire's 67 items on a 9- point scale ranging from 1 (applies very closely to me) to 9 (doesn't apply to me at all). Higher scores represent better adjustment. The Academic Adjustment sub-scale contains 24 items assessing a student's success in coping with various educational demands (e.g., "Lately I have been having doubts regarding the value of a college education"). The Social Adjustment sub-scale contains 20 items evaluating a student's success in coping with the interpersonal and social demands inherent in the college experience ("I am meeting as many people, and making as many friends, as I would like at the college"). The Personal- Emotional Adjustment sub-scale contains 15 items assessing general psychological distress ("I have been feeling tense or nervous lately"). The Institutional Adjustment sub-scale consists of 15 items dealing with the degree of a student's commitment to educational- institutional goals ("Now I'm happy with my decision to attend this college"). Baker and Siryk (1989) reported an alpha of .92-.95 for the full scale, $.81-.90$ for the academic adjustment, $.83-.90$ for the social adjustment, $.77-.86$ for personal- emotional, and $.85-.91$ for institutional adjustment sub-scales. Validity was established based on significant correlations between sub-scales and relevant measures (see Baker \& Siryk, 1989). In the current study, internal reliability for the entire questionnaire was .94 , for academic adjustment .93 , for social adjustment .86, for personal- emotional .91 , and for institutional adjustment .77 .

5.2.3 Motivated Strategies for Learning Questionnaire (MSLQ) (Pintrich, Smith, Garcia, \& McKeachie, 1993). The scale consists of 81 self-report items designed to measure a college student's motivational orientations and the use of different learning strategies. The MSLQ is divided into two broad categories: (1) Motivation, which includes intrinsic goal orientation, extrinsic goal orientation, task value, learning beliefs, self- efficacy for learning and performance, and test anxiety, and (2) Learning strategies, including rehearsal, elaboration, organization, critical thinking, metacognitive self-regulation, time/study environmental management, effort regulation, peer learning, and help seeking. In the current study, we used only one of the sub-scales from the first category: Motivation, "self-efficacy for learning and performance," which consisting of eight items. The items comprising this sub-scale assess two aspects of expectancy: expectancy for success and self-efficacy. The authors of this instrument examined validity and reliability separately for each category and for each sub-scale and found a correlation between "self-efficacy for learning and performance" and grades. Because we examined the effect of learning self-efficacy on academic achievement, this category was the proper one to use. Students rated themselves on a 7-point Likert scale, from 1 ("not at all true of me") to 7 ("very true of me"). A higher score indicates a higher level of academic self-efficacy. The authors of the MSLQ reported an internal consistency of .93 for this sub-scale. Validity was based on a correlation between "self-efficacy for learning and performance" and final grades in courses $(\mathrm{r}=.41)$ (Pintrich et al., 1993). In the current student, internaly consistency was .92 .

5.2.4 Experiences in Close Relationships Scale (ECR) (Brennan, Clark, \& Shaver, 1998). This scale consists of 36 self-report items assessing adult attachment on two sub-scales: Anxiety (18 items) and Avoidance (18 items). Participants responded to a 7- point Likert scale ranging from 1 (disagree strongly) to 7 (agree strongly). Higher scores indicate higher attachment-anxiety and attachment-avoidant styles. The authors of the ECR reported an internal consistency of .94 for Avoidance and .91 for Anxiety (Brennan et al., 1998). In the current study, alpha was .93 for each sub-scale. The construct validity was based on correlations between this scale and 60 other assessment tools measuring attachment styles (Brennan et al., 1998).

5.2.5 The Multidimensional Scale for Perceived Social Support (MSPSS) (Zimet, Dahlem, Zimet, \& Farley, 1988) includes 12 items designed to assess perceptions of social support from three specific sources: family, friends, and significant other. Each of these sources is evaluated by four items. Answers are listed on a 7-point Likert-type scale ranging from 1 (very strongly disagree) to 7 (very strongly agree). Higher scores indicate greater levels of perceived social support ("My friends really try to help me"; "I can talk about my problems with my family"). The scale's total 
reliability is .88 and for Significant Other, Family, and Friends, it is $.91, .87$, and .85 , respectively (Zimet et al., 1988). In the present study, an alpha of .95 was obtained for the total scale, and values of $.91, .88$, and .90 for Significant Other, Family, and Friends, respectively. Validity was based on a negative correlation between this scale and the anxiety/depression scale. Obtaining family support was significantly and negatively correlated with depression $(\mathrm{r}=$ $-.24)$ and anxiety $(\mathrm{r}=-.18)$; receiving support from friends had a significant negative correlation with depressive symptoms $(r=-.24)$, but not with anxiety. The support of meaningful people was correlated significantly and negatively with depression $(\mathrm{r}=-.13)$ (Zimet et al., 1988).

5.2.6 Institutional Support Questionnaire (Krisher \& Shechtman, 2012) is a self -report instrument developed for the present study. The questionnaire consists of five items assessing the individual and group assistance and exam accommodation given to students by the academic institution ("What types of individual assistance have you received during your academic studies"?). The higher the score, the more institutional support the student received.

\subsection{Procedure}

Data were collected in one year using both hard copy and electronic questionnaires. Both versions were identical. The hard copy questionnaires were distributed in several institutions through the Center for Students with Disabilities. The electronic copies were sent out to students diagnosed with LD in most institutions of higher education in Israel, in the attempt to capture a representative sample of students in the country. Students with LD who completed the questionnaires were requested to pass it on to a friend at the same college who had not been diagnosed with LD. A similar procedure was used for the electronic version. This particular method of creating a control group was necessary in order to establish a control group that is similar to the experimental group in background variables (same school and class) as well as personal characteristics. Students returned the electronic questionnaires to the researcher via email. A total of 95 printed and 579 electronic questionnaires were collected.

\section{Results}

The first hypothesis suggested that both the academic achievement and adjustment scores of students with LD would be lower than those of students with no LD. This hypothesis was tested using the analysis of variance (one-way ANOVA). Results showed that both scores were indeed lower for students with LD: academic achievement: $M=81.61$ $(S D$ 7.87) vs. $M=86.05$ ( $S D$ 6.70); adjustment: $M=365.51(S D=104.45)$ vs. $M=395.29(S D=101.84)$. These differences were significant $(F=53.61 p<.001$ and $F=14.02, p<.001)$ for academic achievement and adjustment, respectively.

The second hypothesis held that two internal factors (attachment style and academic self-efficacy) would contribute to the explained variance of academic achievement and adjustment. To examine this hypothesis, a multiple regression analysis was conducted on the academic achievement and adjustment of each group (see Table 1). Results showed that academic self-efficacy contributed significantly to the explained variance of academic achievement among both groups of students, whereas attachment styles did not contribute to the prediction of academic achievement. Anxious attachment style, avoidance attachment style, and academic self-efficacy all made a significant contribution to the explained variance of adjustment to the academic setting among students with LD. For students with no LD, as well, these three variables made a significant contribution to the explained variance of adjustment to higher academic education.

Table 1. Multiple Regression Analysis for academic achievement and adjustment

\begin{tabular}{|c|c|c|c|c|c|c|c|c|c|c|c|c|}
\hline \multirow[b]{3}{*}{ Variable } & \multicolumn{6}{|c|}{ Academic Achievement } & \multicolumn{6}{|c|}{ Adjustment } \\
\hline & \multicolumn{3}{|c|}{ Students with LD } & \multicolumn{3}{|c|}{ Students without LD } & \multicolumn{3}{|c|}{ Students with LD } & \multicolumn{3}{|c|}{ Students without LD } \\
\hline & $B$ & $S E$ & $\beta$ & $B$ & $S E$ & $\beta$ & $B$ & $S E$ & $\beta$ & $B$ & $S E$ & $\beta$ \\
\hline $\begin{array}{l}\text { Anxious } \\
\text { attachment style }\end{array}$ & -0.36 & 0.35 & -0.06 & 0.24 & 0.36 & 0.04 & -10.9 & 3.58 & $-0.14 * *$ & -20.16 & 4.23 & $-0.25 * *$ \\
\hline $\begin{array}{l}\text { Avoidance } \\
\text { attachment style }\end{array}$ & -0.18 & 0.38 & -0.02 & -0.08 & 0.36 & $-0.15^{*}$ & -13.42 & 3.95 & $-0.16^{* *}$ & -13.15 & 4.23 & -0.16 \\
\hline $\begin{array}{l}\text { Academic } \\
\text { self-efficacy }\end{array}$ & 2.81 & 0.30 & $0.51 * * *$ & 2.32 & 0.35 & $0.37 * * *$ & 39.97 & 3.06 & $0.55 * * *$ & 41.88 & 4.20 & $0.43^{* * *}$ \\
\hline$R^{2}$ & & 0.30 & & & 0.17 & 0.52 & & & & & 0.46 & \\
\hline$F$ & & $41.36^{* * *}$ & & & $20.77 * * *$ & & & $123.29 * * *$ & & & $94.84 * *$ & \\
\hline
\end{tabular}

${ }^{* *} p<.01 ; * * * p<.001$. 
According to the third hypothesis, perceived social support would contribute to the explained variance of both academic achievement and adjustment. In order to test this hypothesis, a linear regression with one independent variable (Bivariate Regression) was conducted (see Table 2), the results of which indicated that perceived social support contributed significantly to the explained variance of academic achievement and adjustment to the academic setting among students with and without LD.

Table 2. Bivariate Regression Analysis for academic achievement and adjustment

\begin{tabular}{|c|c|c|c|c|c|c|c|c|c|c|c|c|}
\hline \multirow[b]{3}{*}{ Variable } & \multicolumn{6}{|c|}{ Academic Achievement } & \multicolumn{6}{|c|}{ Adjustment } \\
\hline & \multicolumn{3}{|c|}{ Students with LD } & \multicolumn{3}{|c|}{ Students without LD } & \multicolumn{3}{|c|}{ Students with LD } & \multicolumn{3}{|c|}{ Students without LD } \\
\hline & $B$ & $S E$ & $\beta$ & $B$ & $S E$ & $\beta$ & $B$ & $S E$ & $\beta$ & $B$ & $S E$ & $\beta$ \\
\hline Social support & 0.20 & 0.02 & $0.50 * * *$ & 0.11 & 0.02 & $0.26 * * *$ & 3.84 & 0.20 & $0.72 * * *$ & 2.92 & 0.31 & $0.45 * * *$ \\
\hline$R^{2}$ & \multicolumn{3}{|c|}{0.25} & \multicolumn{3}{|c|}{0.06} & \multicolumn{3}{|c|}{0.52} & \multicolumn{3}{|c|}{0.20} \\
\hline$F$ & \multicolumn{3}{|c|}{$97.10^{* * *}$} & \multicolumn{3}{|c|}{$21.28 * * *$} & \multicolumn{3}{|c|}{$370.36^{* * *}$} & \multicolumn{3}{|c|}{$85.48 * * *$} \\
\hline
\end{tabular}

The fourth hypothesis suggested that institutional support would contribute to academic achievement, adjustment, and academic self-efficacy among students with LD (see Table 3). Results showed that institutional support contributed significantly to the explained variance of adjustment to academic setting and to academic self-efficacy. It should be noted that only exam accommodation made a significant contribution to the explained variance of academic achievement, whereas all three variables (exam accommodation, individual help, and group assistance) contributed significantly to the explained variance of adjustment to academic institution. As for academic self-efficacy, exam accommodation and individual assistance made a significant contribution to the sense of academic self-efficacy among students with LD.

Table 3. Regression Analysis for academic achievement, adjustment, and academic self-efficacy

\begin{tabular}{|c|c|c|c|c|c|c|c|c|c|}
\hline \multirow[b]{2}{*}{ Variable } & \multicolumn{3}{|c|}{ Academic Achievement } & \multicolumn{3}{|c|}{ Adjustment } & \multicolumn{3}{|c|}{ Academic self-efficacy } \\
\hline & $B$ & $S E$ & $\beta$ & $B$ & $S E$ & $\beta$ & $B$ & $S E$ & $\beta$ \\
\hline $\begin{array}{l}\text { Exam } \\
\text { accommodation }\end{array}$ & 1.00 & 0.25 & $0.22 * * *$ & 8.97 & 3.00 & $0.15^{* *}$ & 0.21 & 0.04 & $0.25 * * *$ \\
\hline $\begin{array}{l}\text { Individual } \\
\text { assistance }\end{array}$ & 0.36 & 0.25 & 0.08 & 10.43 & 3.31 & $0.18 * *$ & 0.15 & 0.04 & $0.19^{* *}$ \\
\hline $\begin{array}{l}\text { Group } \\
\text { assistance }\end{array}$ & 0.89 & 0.43 & $0.13 *$ & 15.12 & 5.39 & $0.16^{* *}$ & 0.03 & 0.07 & 0.02 \\
\hline$R^{2}$ & & 0.09 & & & 0.12 & & & 0.11 & \\
\hline$F$ & & 10.29 & & & $16.21 * * *$ & & & $14.83 * * *$ & \\
\hline
\end{tabular}

A Structural Equation Analysis (SEM) (Arbuckle, 2003; Bollen, 1989) was used to confirm our model. Because the chi-square test is affected by the type of model and by sample size, the present research used three measures to evaluate how well the data fit the proposed model: the normed fit index (NFI), the non-normed fit index (NNFI), and the comparative fit index (CFI) (Byrne, 2001; McDonald \& Ho, 2002). These measures should be higher than 0.9 to represent a good fit. In addition, we used the RMSEA (Root Mean Square Error of Approximation) index, which should be less than 0.05 to represent a good fit (Boomsma, 2000). The relationships between variables in the model $(\beta)$ were expected to have a significance of $\mathrm{p}<0.05$. The results of the current study indicated that the overall model fit the data reasonably well. The following indices were utilized as evidence of fit: NFI $=.96$, NNFI $=.97, \mathrm{CFI}=.98$, and RMSEA $=.03$.

The structural parameter estimates are presented in Table 4. The findings showed the following: (a) Program of study $(\beta=.13 ; p<.01)$, social support $(\beta=.26 ; p<.001)$, and academic self-efficacy $(\beta=.37 ; p<.001)$ had a direct impact 
on academic achievement; examination of the structural relations also revealed that attachment style exerted an indirect impact on academic achievement when the mediating variable was social support. (b) Anxious attachment style $(\beta=-.09 ; p<.05)$, academic self-efficacy $(\beta=.034 ; p<.001)$, social support $(\beta=.42 ; p<.001)$, and group assistance $(\beta=.10 ; p<.01)$ showed a direct impact on adjustment to academic setting; in addition, avoidance attachment style had an indirect impact on adjustment when the mediating variable was social support. (c) Anxious attachment style $(\beta=-.13 ; p<.01)$, avoidance attachment style $(\beta=-.27 ; p<.001)$, and academic self-efficacy had a direct impact on perceived social support. (d) Program of study $(\beta=.28 ; p<.001)$ had a significant direct contribution to the prediction of exam accommodation: students who studied humanities and social sciences tended to report greater use of exam accommodation than did students who studied sciences. Academic self-efficacy $(\beta=.25 ; p<.001)$, as well, had a significant direct impact on exam accommodation, meaning that students who reported higher levels of academic self-efficacy tended to report greater use of the exam accommodation proffered them. For individual assistance, gender was found to make a significant direct contribution to the prediction $(\beta=.14 ; p<.01)$, suggesting that male students reported greater use of individualized assistance than did female students. Avoidance attachment style $(\beta=-.12 ; p<.05)$ and academic self-efficacy $(\beta=.17 ; \mathrm{p}<.01)$ each had a significant direct impact on individual assistance.

Table 4. The structural parameter

\begin{tabular}{|c|c|c|c|c|c|c|}
\hline Dependent Variable & Predictor variable & $\mathrm{B}$ & SE & $\beta$ & C.R. & $\mathrm{R}^{2}$ \\
\hline \multirow[t]{4}{*}{ Social support } & $\begin{array}{c}\text { Anxious attachment } \\
\text { style }\end{array}$ & -1.86 & 0.65 & $-0.13^{-* *}$ & -2.86 & \multirow{4}{*}{0.55} \\
\hline & Avoidance attachment & -4.27 & 0.72 & $-0.27^{* * *}$ & -5.92 & \\
\hline & \multicolumn{5}{|l|}{ style } & \\
\hline & Academic self-efficacy & 6.56 & 0.55 & $0.49^{* * *}$ & 11.75 & \\
\hline \multirow[t]{2}{*}{ Exam accommodation } & Field of study & 1.03 & 0.18 & $0.28^{* * *}$ & 5.59 & \multirow{2}{*}{0.14} \\
\hline & Academic self-efficacy & 0.29 & 0.06 & $0.25^{* * *}$ & 4.92 & \\
\hline \multirow[t]{3}{*}{ Individual assistance } & Gender & 0.52 & 0.19 & $0.14^{* *}$ & 2.62 & \multirow{3}{*}{0.08} \\
\hline & $\begin{array}{c}\text { Avoidance attachment } \\
\text { style }\end{array}$ & -0.17 & 0.08 & $-0.12 *$ & -2.05 & \\
\hline & Academic self-efficacy & 0.21 & 0.07 & $0.17^{* *}$ & 2.90 & \\
\hline \multirow[t]{3}{*}{ Academic achievement } & Social support & 0.10 & 0.02 & $0.26^{* * *}$ & 4.02 & \multirow{3}{*}{0.35} \\
\hline & Field of study & 2.13 & 0.75 & $0.13^{* *}$ & 2.84 & \\
\hline & Academic self-efficacy & 1.96 & 0.34 & $0.37^{* * *}$ & 5.75 & \\
\hline \multirow[t]{4}{*}{ Adjustment } & Social support & 2.22 & 0.25 & $0.42^{* * *}$ & 8.78 & \multirow{4}{*}{0.62} \\
\hline & $\begin{array}{c}\text { Anxious attachment } \\
\text { style }\end{array}$ & -7.26 & 2.93 & $-0.09 *$ & -2.47 & \\
\hline & Group assistance & 9.83 & 3.06 & $0.10^{* *}$ & 3.21 & \\
\hline & Academic self-efficacy & 24.25 & 3.24 & $0.34 * * *$ & 7.48 & \\
\hline
\end{tabular}

\section{Discussion}

College students with LD have begun to receive more attention in higher education research because of the increased numbers of these learners pursuing a college degree (Weyandt \& DuPaul, 2008). Based on the multi-dimensional developmental model, there are mutual relations between an individual and environmental characteristics that affect the academic functioning and adjustment of students with LD. Such students, who constitute a unique sub-group in higher education, require particular attention (Costello \& Stone, 2012). Accordingly, the purpose of the present study was to advance further understanding of the academic functioning and adjustment of college students with LD. We 
were particularly interested in understanding the role of both internal (academic self-efficacy and attachment style) and external (social support and institutional support) factors in the adjustment and academic achievement of students with LD in the higher education setting.

Our findings showed that academic achievement and adjustment scores of students who report having an LD were lower than those of students who do not report having an LD. These findings are consistent with prior research showing that students with LD frequently have lower grade point averages, have more difficulties in the process of adapting to the academic setting, and are more likely to face the possibility of academic probation than students without LD (Fraizer et al., 2007; Heiman, 2006b; Turnbull et al., 2010; Weyandt \& DuPaul, 2008). In addition, the present findings support our hypothesis regarding the unique function of academic self-efficacy as an explanatory variable of the academic achievement and adjustment to the academic setting of students in general, both those with and those without LD. Self-efficacy plays a role in the way people feel, think, behave, and motivate themselves (Costello \& Stone, 2012). The literature suggests that self-efficacy is a mediating variable between cognition and performance and is linked to goal setting and success in college (DeWitz, Wollsey, \& Walsh, 2009; Sullivan \& Guerra, 2007). If a student believes that he/she will be able to perform academic tasks successfully, motivation increases. Increased motivation further strengthens metacognition, regulation and self-monitoring, which in turn leads both to attributing successes to self-efforts and to establishing a more internal locus of control with regard to academic success (Hall \& Webster, 2008).

Regarding attachment style, we expected that students with higher degrees of anxiety and avoidance would have lower achievements and also report a lower level of adjustment. Our findings suggest that attachment style is associated with adjustment to college, but not with academic achievement. These findings are consistent with the results of prior research, suggesting that attachment anxiety and avoidance are positively related to maladjustment and emotional distress, but not to learning (Al-Yagon, 2012). Attachment theory assumes that infants internalize their interactions with a significant other, leading to internal working models that are manifested in social interactions through adulthood. As hypothesized, the current results emphasize the crucial role of student's attachment style to their adjustment to college life. Students with LD often demonstrate socio-emotional difficulties (Capozzi, Casini, Romani, De Gennaro, Nicolais, \& Solano, 2008; Estell, Jones, Pearl, Van Acker, Farmer, \& Rodkin, 2008), and therefore one should note that non-secure attachment may be a risk factor.

We further hypothesized that social support would contribute to the explained variance of academic achievement and adjustment. Our findings indicate that social support had a main effect on both the adjustment and academic achievement of all college students. This finding is consistent with research on students without disabilities (Mattanah, Ayers, Brand, Brooks, Quimby, \& McNary, 2010; Wilks \& Spivey, 2010; Yalcin, 2011), but it extends previous findings by showing that social support is a salient predictor of adjustment and achievement among college students with LD. Thus, social support received from family, friends, or teachers who believe in the young person's ability to succeed may act as a protective factor for students with LD and, therefore, is more significant in this population. Indeed, previous research also indicated a relationship between social support and adjustment among adults with LDs (Murray et al., 2013; Wilks, \& Spivey 2010).

Our last hypothesis suggested that institutional support would contribute to academic achievements, adjustment, and the academic self-efficacy of students with LD. This finding, too, is consistent with previous research indicating that students who consistently attended an academic support center had higher rates of success than those who did not attend or who did not attend consistently. The students who received institutional support tended to have higher grade-point averages and persisted to graduation (Troiano, Liefeld, \& Trachtenberg, 2010). In addition, it was found that the support services staff can help increase self-efficacy through setting appropriate and realistic academic goals (Costello \& Stone, 2012). Receiving appropriate mental support and being offered exam accommodations can prove critical to postsecondary school success and to the retention of students with LD who are enrolled in higher education institutions (Lindstrom, 2007).

The present study has several limitations that need to be noted. First, the data was based on self-report measures, as are most studies based on large samples. Also, the variables explored in this study are based on self-perceptions. Self efficacy, perceived social support, attachment, and adjustment are all measures based on subjective perceptions. In the current study, GPA was also based on self-report; this is a limitation because of the possible bias in such cases. Indeed, adding other report data, such as actual support received from family, friends, or institution, or using grades from transcripts, might have strengthened the results but this is difficult to achieve in large-scale studies. Second, the way data were collected (i.e., questionnaires were sent out to many institutions) created a problem of self-selection. Yet, this was a necessary step; to learn about institutional support we needed a large number of institutions. Thus, the sample 
might have been biased by students who selected to participate in the study. However, ethical consideration require free choice of students to participate in such study. Third, by definition, students who are eligible to work with the centers for learning disabilities had undergone a formal diagnosis. However, no distinction was made among different types of disabilities. Further research is needed to accurately distinguish among sub-types of disabilities, such as LD versus attention deficit hyperactivity disorder (ADHD). ADHD is known as a disorder possessing unique characteristics (Prevatt, Reaser, Proctor, \& Petscher, 2007; Weyandt \& DuPaul, 2008). A fourth concern is the lack of information on drop-out rates. Future research should examine this element in addition to GPA. The information may shed light on factors leading to the success or failure of students with learning disabilities in academic settings.

In summary, the uniqueness of the present study lies in demonstrating the integration of individual and environmental characteristics for predicting academic achievement and adjustment to higher education among students with learning disabilities. The findings confirm the importance of academic self-efficacy, attachment style, and both social and institutional support in the adjustment of students with LD and in their academic success. They also highlight the contribution of these factors to students who do not have an LD. Most of these factors can be put to beneficial use by academic institutions that care about their students, whether or not these learners have LD. Encouragement and support may be provided through the creation of a positive social climate, the development of a language of support, and being attuned to the individual needs of students. Further research should identify additional factors that may shed light on the academic, social, and psychological functioning of students with LD in settings of higher education.

\section{References}

Ainsworth, M. D., Blehar, M. C., Waters, E., \& Wall, S. (1978). Patterns of attachment: A psychological study of the strange situation. Hillsdale, NJ: Erlbaum.

Al-Yagon, M. (2012). Adolescents with learning disabilities: Socioemotional and behavioral functioning and attachment relationships with fathers, mothers, and teachers. Journal of Youth and Adolescence, 41(10), 1294-1311. http://dx.doi.org/10.1007/s10964-012-9767-6

Al-Yagon, M. (2014). Child-mother and child-father attachment security: Links to internalizing adjustment among children with learning disabilities. Child Psychiatry \& Human Development, 45(1), 119-131. http://dx.doi.org/10.1007/s10578-013-0383-9

Arbuckle, J. L. (2003). AMOS 5 update to the AMOS User's Guide. Chicago: Small Waters Co.

Baker, R. W., \& Siryk, B. (1989). SACQ student adaptation to College Questionnaire Manual. Los Angeles, CA: Western Psychological Services.

Bakker, A. B., Demerouti, E., \& Euwema, M. C. (2005). Job resources buffer the impact of job demands on burnout. Journal of Occupational Health Psychology, 10(2), 170. http://dx.doi.org/10.1037/1076-8998.10.2.170

Bandura, A. (1993). Perceived self efficacy in cognitive development and functioning. Educational Psychologist, 28(2), 117-148. http://dx.doi.org/10.1207/s15326985ep2802_3

Bollen, K. A. (1989). Structural equations with latent variables. New York, NY: Wiley. http://dx.doi.org/10.1002/9781118619179

Boomsma, A. (2000). Reporting analyses of covariance structures. Structural Equation Modeling, 7, 461-482. http://dx.doi.org/10.1207/S15328007SEM0703_6

Bowlby, J. (1980). Attachment and loss: Loss. New York, NY: Basic Books.

Brennan, K. A., Clark, C. L., \& Shaver, P. R. (1998). Self-reported measurement of adult attachment: An integrative overview. In J.A. Simpson \& E.S. Rholes (Eds.), Attachment theory and close relationships (pp. 46-76). NY: Guilford Press.

Buchanan, T., Charles, M. S., Rigler, M., \& Hart, C. (2010). Why are older faculty members more accepting of students with attention-deficit hyperactivity disorder? A life-course interpretation. International Journal of Disability, Development, and Education, 57(4), 351-369. http://dx.doi.org/10.1080/1034912X.2010.524407

Byrne, B. (2001). Structural equation modeling with AMOS: Basic concepts, applications, and programming. Mahwah, NJ: Erlbaum.

Capozzi, F., Casini, M. P., Romani, M., De Gennaro, L., Nicolais, G., \& Solano, L. (2008). Psychiatric comorbidity in learning disorder: Analysis of family variables. Child Psychiatry and Human Development, 39(1), 101-110. http://dx.doi.org/10.1007/s10578-007-0074-5 
Costello, C. A., \& Stone, S. L. (2012). Positive psychology and self-efficacy: Potential benefits for college students with attention deficit hyperactivity disorder and learning disabilities. Journal of Postsecondary Education and Disability, 25(2), 119-129.

DeWitz, S. J., Woolsey, M. L., \& Walsh, W. B. (2009). College student retention: An exploration of the relationship between self-efficacy beliefs and purpose in life among college students. Journal of College Student Development, 50(1), 19-34. http://dx.doi.org/10.1353/csd.0.0049

Estell, D. B., Jones, M. H., Pearl, R., Van Acker, R., Farmer, T. W., \& Rodkin, P. C. (2008). Peer groups, popularity, and social preference trajectories of social functioning among students with and without learning disabilities. Journal of Learning Disabilities, 41(1), 5-14. http://dx.doi.org/10.1177/0022219407310993

Estrada, L., Dupoux, E., \& Wolman, C. (2006). The relationship between locus of control and personal emotional adjustment and social adjustment to college life in students with and without learning disabilities. College Student Journal, 40(1), 43-54.

Frazier, T. W., Youngstrom, E. A., Glutting, J. J., \& Watkins, M. W. (2007). ADHD and achievement: Meta-analysis of the child, adolescent, and adult literatures and a concomitant study with college students. Journal of Learning Disabilities, 40, 49-65. http://dx.doi.org/10.1177/00222194070400010401

Gresham, D., \& Gullone, E. (2012). Emotion regulation strategy use in children and adolescents: The explanatory roles of personality and attachment. Personality and Individual Differences, 52(5), 616-621. http://dx.doi.org/10.1016/j.paid.2011.12.016

Hall, C. W., \& Webster, R. E. (2008). Metacognitive and affective factors of college students with and without learning disabilities. Journal of Postsecondary Education and Disability, 21(1), 32-41.

Hazan, C., \& Shaver, P. R. (1994). Attachment as an organizational framework for research on close relationships. Psychological Inquiry, 5, 1-22. http://dx.doi.org/10.1207/s15327965pli0501_1

Heiman, T. (2006a). Assessing learning styles among students with and without learning disabilities at a distance-learning university. Learning Disability Quarterly, 29(1), 55-63. http://dx.doi.org/10.2307/30035532

Heiman, T. (2006b). Social support networks, stress, sense of coherence and academic success of university students with and without learning disabilities. Social Psychology of Education, 9(4), 461-478. http://dx.doi.org/10.1007/s11218-006-9007-6

Hojati, M., \& Abbasi, M. (2013). Comparisons of Self-Efficacy and Hope among Students with and without Learning Disabilities. Journal of Special Education and Rehabilitation, 14(1-2), 66-77. http://dx.doi.org/10.2478/v10215-011-0034-2

Karatepe, O. M., \& Olugbade, O. A. (2009). The effects of job and personal resources on hotel employees' work engagement. International Journal of Hospitality Management, 28(4), 504-512. http://dx.doi.org/10.1016/j.ijhm.2009.02.003

Khalili, L. (2006). The relationships between differentiation, collectivism and adjustment to university life among Arab students (Unpublished master's thesis, University of Haifa, Israel). Retrieved from http://nprimofe.haifa.ac.il/primo_library /libweb /action/search.do?vid=NHAU

Klassen, R. M., \& Lynch, S. L. (2007). Self-efficacy from the perspective of adolescents with LD and their specialist teachers. Journal of Learning Disabilities, 40(6), 494-507. http://dx.doi.org/10.1177/00222194070400060201

Lindstrom, J. H. (2007). Determining appropriate accommodations for postsecondary students with reading and written expression disorders. Learning Disabilities Research \& Practice, 22(4), 229-236. http://dx.doi.org/10.1111/j.1540-5826.2007.00251.x

Main, M., \& Solomon, J. (1986). Discovery of a new, insecure disorganized/disoriented attachment pattern. In M. Yogman \& T. B. Brazelton (Eds.), Affective development in infancy (pp. 95-124). Norwood, NJ: Abex Press.

Mattanah, J. F., Ayers, J. F., Brand, B. L., Brooks, L. J., Quimby, J. L., \& McNary, S. W. (2010). A social support intervention to ease the college transition: Exploring main effects and moderators. Journal of College Student Development, 51(1), 93-108. http://dx.doi.org/10.1353/csd.0.0116

McDonald, R. P., \& Ho, M. R. (2002). Principles and practice in reporting structural equation analyses. Psychological Methods, 7, 64-82. http://dx.doi.org/10.1037/1082-989X.7.1.64

Murray, C., Lombardi, A., Bender, F., \& Gerdes, H. (2013). Social support: Main and moderating effects on the relation 
between financial stress and adjustment among college students with disabilities. Social Psychology of Education, 16(2), 277-295. http://dx.doi.org/10.1007/s11218-012-9204-4

Pintrich, P. R., Smith, D. A., Garcia, T., \& McKeachie, W. J. (1993). Reliability and predictive validity of the Motivated Strategies for Learning Questionnaire (MSLQ). Educational and Psychological Measurement, 53(3), 801-813. http://dx.doi.org/10.1177/0013164493053003024

Prevatt, F., Reaser, A., Proctor, B., \& Petscher, Y. (2007). The learning/study strategies of college students with ADHD. The ADHD Report, 15(6), 6-9. http://dx.doi.org/10.1521/adhd.2007.15.6.6

Raue, K., \& Lewis, L. (2011). Students with disabilities at degree-granting postsecondary institutions (NCES 2011-018). U.S. Department of Education, National Center for Education Statistics. Washington, DC: U.S. Government Printing Office.

Sarason, I. G., \& Sarason, B. R. (2009). Social support: Mapping the construct. Journal of Social and Personal Relationships, 26(1), 113-120. http://dx.doi.org/10.1177/0265407509105526

Schunk, D. H., \& Pajares, F. (2009). Self- efficacy theory. In K. R. Wentzel \& A. Wigfield (Eds.), Handbook of motivation at school (pp. 35-53). NY: Routledge.

Shepler, D. K., \& Woosley, S. A. (2012). Understanding the early integration experiences of college Students with disabilities. Journal of Postsecondary Education and Disability, 25(1), 37-50.

Sullivan, J. R., \& Guerra, N. S. (2007). A closer look at college students: Self-efficacy and goal orientation. Journal of Advanced Academics, 18(3), 454-476.

Troiano, P. F., Liefeld, J. A., \& Trachtenberg, J. V. (2010). Academic support and college success for postsecondary students with learning disabilities. Journal of College Reading \& Learning, 40(2), 35-44. http://dx.doi.org/10.1080/10790195.2010.10850329

Turnbull, A., Turnbull, R., \& Wehmeyer, M. (2010). Exceptional lives: Special education in today's schools (6th ed.). Columbus, OH: Pearson.

Vance, T. A., \& Weyandt, L. (2008). Professor perceptions of college students with attention deficit hyperactivity disorder. Journal of American College Health, 57(3), 303-308. http://dx.doi.org/10.3200/JACH.57.3.303-308

Weyandt, L. L., \& DuPaul, G. J. (2008). ADHD in college students: Developmental findings. Developmental Disabilities Research Reviews, 14(4), 311-319. http://dx.doi.org/10.1002/ddrr.38

Wilks, S. E., \& Spivey, C. A. (2010). Resilience in undergraduate social work students: Social support and adjustment to academic stress. Social Work Education, 29(3), 276-288. http://dx.doi.org/10.1080/02615470902912243

Yalcin, I. (2011). Social support and optimism as predictors of life satisfaction of college students. International Journal for the Advancement of Counselling, 33(2), 79-87. http://dx.doi.org/10.1007/s10447-011-9113-9

Zimet, G. D., Dahlem, M. W., Zimet, S. G., \& Farley, G. K. (1988). The multidimensional scale for perceived social support. Journal of Personality Assessment, 52(1), 30-41. http://dx.doi.org/10.1207/s15327752jpa5201_2

Zimmerman, B. J. (2008). Investigating self-regulation and motivation: Historical background, methodological developments, and future prospects. American Educational Research Journal, 45, 166-183. http://dx.doi.org/10.3102/0002831207312909 